\title{
Plasma Rich in Growth Factors in Macular Hole Surgery
}

\author{
Ronald M. Sánchez-Ávila ${ }^{1,2, *}$, Carlos A. Robayo-Esper ${ }^{1}$, Eva Villota-Deleu ${ }^{1}$, Álvaro Fernández-Vega Sanz ${ }^{1}$, \\ Álvaro Fernández-Vega González ${ }^{1}{ }^{(}$, Borja de la Sen-Corcuera ${ }^{2,3}{ }^{\circledR}$, Eduardo Anitua ${ }^{2,3}$ and Jesús Merayo-Lloves ${ }^{1}$
}

1 Ophthalmology Research Foundation, Fernández-Vega University Institute, University of Oviedo, 33071 Oviedo, Spain; carlosrobayo@hotmail.com (C.A.R.-E.); milideleu@yahoo.com (E.V.-D.); afdzvega@gmail.com (Á.F.-V.S.); afdezvega@gmail.com (Á.F.-V.G.); merayo@fio.as (J.M.-L.)

2 Regenerative Medicine Laboratory, Biotechnology Institute (BTI), 01007 Vitoria, Spain; bdelasen@bti-health.com (B.d.1.S.-C.); eduardoanitua@eduardoanitua.com (E.A.)

3 Regenerative Medicine Laboratory, University Institute for Regenerative Medicine and Oral Implantology (UIRMI), 01007 Vitoria, Spain

* Correspondence: rsanchez@bti-health.com; Tel./Fax: +34-945-160-652

check for updates

Citation: Sánchez-Ávila, R.M.; Robayo-Esper, C.A.; Villota-Deleu, E.; Fernández-Vega Sanz, Á.; Fernández-Vega González, Á.; de la Sen-Corcuera, B.; Anitua, E.; Merayo-Lloves, J. Plasma Rich in Growth Factors in Macular Hole Surgery. Clin. Pract. 2022, 12, 57-69. https://doi.org/10.3390/ clinpract12010007

Received: 21 October 2021 Accepted: 5 January 2022 Published: 10 January 2022

Publisher's Note: MDPI stays neutral with regard to jurisdictional claims in published maps and institutional affiliations.

Copyright: () 2022 by the authors. Licensee MDPI, Basel, Switzerland. This article is an open access article distributed under the terms and conditions of the Creative Commons Attribution (CC BY) license (https:// creativecommons.org/licenses/by/ $4.0 /)$.

\begin{abstract}
The aim of this study was to evaluate the use of PRGF (plasma rich in growth factors) as an adjuvant to PPV (pars plana vitrectomy) in recurrent, persistent, or poor prognosis $\mathrm{MH}$ (macular hole). Patients with MH were treated with PPV plus adjuvant therapy (PRGF membrane (mPRGF) and injectable liquid PRGF (iPRGF)). The anatomical closure of $\mathrm{MH}$ and postoperative BCVA (bestcorrected visual acuity) were evaluated. Eight eyes (eight patients) were evaluated: myopic $\mathrm{MH}$ $(\mathrm{MMH}, n=4)$, idiopathic $\mathrm{MH}(\mathrm{IMH}, n=2)$, iatrogenic $n=1$, traumatic $n=1$. The mean age was $53.1 \pm 19.3$ years. Hence, $66.7 \%(n=4)$ of patients previously had internal limiting membrane peeling. Five patients (62.5\%) received mPRGF and iPRGF, and three patients (37.5\%) received iPRGF. Gas tamponade (C3F8) was placed in seven cases and one case of silicone oil. Anatomic closure of $\mathrm{MH}$ was achieved in seven eyes $(87.5 \%)$ and BCVA improved in six cases. In the MMH group, visual acuity improved in two lines of vision. Follow-up time was $27.2 \pm 9.0$ months. No adverse events or $\mathrm{MH}$ recurrences were recorded during follow-up. The use of PRGF as an adjuvant therapy to PPV can be useful to improve anatomical closure and visual acuity in MH surgery.
\end{abstract}

Keywords: macular hole; PRGF; retinal regeneration; optical coherence tomography; macular hole surgery

\section{Introduction}

The macular hole $(\mathrm{MH})$ is an anatomical defect in the retina located in the fovea center, which causes a significant decrease in vision [1]. The estimated prevalence in the general population is approximately 3.3 per 1000 inhabitants [2], mainly affecting people over 65 years of age and with two thirds corresponding to women [3]. The $\mathrm{MH}$ can be divided into two categories, namely primary or idiopathic (IMH) and secondary [3]. The IMH is caused by vitreous traction in the center of the fovea in the anteroposterior and tangential direction [1]. Classically, it has been classified in Gass stages (0-4). However, this classification is currently expanded according to the size of MH measured by OCT (optical coherence tomography) [4]. The secondary $\mathrm{MH}$ can be caused by various conditions, such as trauma, myopia, macular schisis, diabetic macular oedema, age-related macular degeneration, central venous occlusion of the retina, or type 2 macular telangiectasias [3].

The standard gold treatment for $\mathrm{MH}$ is pars plana vitrectomy (PPV), with the release of the posterior vitreous, associated or not with peeling of the internal limiting membrane (ILM), together with the use of a gas tamponade [5]. Another method used in surgery is the autologous ILM plug, with favorable clinical results in large MHs [6], persistent full-thickness MHs [7], and refractory MHs [8]. Recurrent IMH rates vary from $8 \%$ to $44 \%$ according to some published studies, possibly related to $\mathrm{MH}$ size $(>400 \mu \mathrm{m})$, the presence 
of subretinal fluid, and retinal detachment [3,9]. In the myopic macular hole (MMH), the anatomical success achieved after PPV can be between $62.5 \%$ and $87.5 \%$, according to some published series, frequently requiring a second intervention to achieve $\mathrm{MH}$ closure $[10,11]$.

To increase the success rate in MH closure, several adjuvant therapies to PPV have been described: transforming growth factor-beta 2 as a chorioretinal adhesive [12], autologous serum, thrombin, and autologous platelet concentrates [13-15]. Plasma rich in growth factors (PRGF) is an autologous blood-derived product, with calcium-based plasma activation and four ophthalmological formulations (injectable liquid, eye drops, clot, and membrane) $[16,17]$. It has a closed production system, with predictability in its manufacture and safety in its use [18]. PRGF has demonstrated anti-inflammatory, anti-fibrotic, and regenerative functions in ocular surface and cornea diseases (dry eye, persistent epithelial defects, neurotrophic keratitis, among others) [19-22]. The use of the PRGF membrane in the closure of $\mathrm{MH}$ in high myopia has also achieved good anatomical and visual results [23].

The use of blood derivatives as an adjunct to IMH surgery has been widely investigated even in clinical trials [24]. However, PRGF is still under evaluation in the treatment of large, recurrent, persistent, or poor prognosis MHs in clinical follow-ups longer than one year. This study aims to describe the anatomical and visual results of the use of PRGF as an adjunct to PPV in patients with MH (large, recurrent, persistent or of poor prognosis). Moreover, we aim to evaluate the restoration potential of the outer retinal layers by OCT images.

\section{Materials and Methods}

This retrospective, single-center, interventional, and case-series study was conducted at the Fernández-Vega University Institute (Oviedo, Spain). The Institutional Review Board approved this study. Patients provided informed consent for the surgical procedure and the use of PRGF. The principles of the Declaration of Helsinki were followed.

\subsection{Patients}

Patients were included between 2011 and 2018 who were required to have a diagnosis of persistent $\mathrm{MH}$ (no primary closure after PPV), recurrent $\mathrm{MH}$ (reopening of $\mathrm{MH}$ after 3 months of PPV), or poor prognosis of closure due to its size (MH large $>400 \mu \mathrm{m}$ of diameter, measured at the narrowest point of the hole). MHs of diverse etiology were selected: myopic, iatrogenic, idiopathic, and traumatic. A complete pre-surgical evaluation was performed, including demographic data, ophthalmological history, slit-lamp examination of the ocular surface, cornea, and fundus in pharmacological dilatation. Data were recorded before and after surgical treatment with PRGF: best-corrected visual acuity (BCVA) was measured in decimals (transformed to LogMAR: logarithm of the minimal angle of resolution); intraocular pressure (IOP) was measured with Goldmann applanation tonometry; analysis was performed by spectral-domain OCT (Cirrus 5000, Carl Zeiss AG, Oberkochen, Germany), making three measurements of $\mathrm{MH}$ (minimum diameter, base diameter, height), state of the lens, and $\mathrm{MH}$ closure. Gained visual acuity lines were also evaluated.

The $\mathrm{MH}$ diagnosis time (months) and the time with the MH opening until surgery with PRGF was performed (months) were also recorded. Additionally, safety data associated with the treatments administered to the patients were recorded. The minimum diameter is the smallest distance between the edges of the $\mathrm{MH}$, and allows its size to be classified as small $(<250 \mu \mathrm{m})$, medium $(250-400 \mu \mathrm{m})$, and large $(>400 \mu \mathrm{m})$ [25]. The base diameter corresponds to the distance between the two edges of the $\mathrm{MH}$ at the level of the retinal pigment epithelium (RPE), and the height is the average of the measurements between the RPE and the ILM at the edges of the hole.

\subsection{Preparation of PRGF}

To prepare the PRGF membrane (mPRGF), $81 \mathrm{~mL}$ of peripheral blood was drawn in $9 \mathrm{~mL}$ tubes with $3.8 \%$ sodium citrate as anticoagulant. Subsequently, the blood was centrifuged at $580 \times g$ at room temperature for $8 \mathrm{~min}$, using the Endoret closed system 
(PRGF, Ophthalmology kit, BTI Biotechnology Institute, S.L., Miñano, Álava, Spain). The manufacturing protocol for the PRGF injectable liquid and membrane manufacturing protocol described by Anitua and $\mathrm{Col}$ was followed [21,26]. The plasma column formed was divided into two fractions: Fraction 2 (F2), defined as the $2 \mathrm{~mL}$ above the leukocyte layer; and Fraction (F1), as the remaining plasma above F2. The F2 fraction was used to prepare the mPRGF, requiring $5 \mathrm{~mL}$ of $\mathrm{F} 2$ previously activated with $10 \%$ calcium chloride Endoret Activator (BTI Biotechnology Institute, S.L., Miñano, Álava, Spain) and incubated in $35 \mathrm{~mm}$ vials for $30 \mathrm{~min}$ at $37^{\circ} \mathrm{C}$ with the Plasmaterm H Heater (BTI Biotechnology Institute). The clot formed was transferred to a shaper and pressed for the $30 \mathrm{~s}$ in order to obtain a $100 \mu \mathrm{m}$ thick membrane. The mPRGF was placed on nitrocellulose disks to be used in the surgery room. The F1 fraction was also activated with Endoret Activator immediately before being used as an injectable PRGF liquid (iPRGF) during surgery.

\subsection{The Surgical Technique Using PRGF in the Macular Hole}

The $10 \%$ povidone-iodine was used for cleaning the ocular surface (10 min before anesthesia application). Retrobulbar anesthesia was performed (mepivacaine hydrochloride, 2\%; B. Braun Melsungen AG; Arnhem, The Netherlands) in all patients, using a maximum of $4 \mathrm{~mL}$ of anesthetic. A complete PPV was performed using 23-gauge valved trocars (Constellation Vision System; Alcon Surgical, Fort Worth, TX, USA); when necessary, endoillumination with a chandelier cannula was used to facilitate bimanual movements. If ILM was present, it was stained with brilliant blue G (Dutch Ophthalmic Research Center $\mathrm{BV}$, Zuidland, The Netherlands). In cases with peeling of internal limiting membrane (P-ILM), an extension of the ILM rhexis and transposition were performed according to the surgeon's criteria. The mPRGF plug was trimmed and rolled for later insertion across to 23-gauge trocars. mPRGF could be manipulated inside the vitreous cavity and placed under perfluorocarbon liquid (PFCL, Carl Zeiss Meditec AG, Jena, Germany) inside the $\mathrm{MH}$. In some cases, iPRGF was added ( 3 drops, leaving it to act for $5 \mathrm{~min}$ to allow a better adhesion). The decision to place the mPRGF or iPRGF was based on the clinical judgment of the surgeon. PFCL-fluid-air exchange was performed at the end of the surgery, leaving gas tamponade (C3F8) or standard silicone oil (Oxane 1300; Bausch + Lomb, Incorporated, Rochester, NY, USA) according to the surgeon's criteria and subsequently placing the patient for $1 \mathrm{~h}$ in the supine position immediately after surgery. The patient had to be maintained in the prone position for the next three days and gradually moved towards the supine position over the following two weeks. There were no intraoperative complications with the surgical technique used. Patients received topical antibiotics and anti-inflammatory treatment during the month after surgery, with a gradual decrease according to protocol. Patients had a minimum follow-up of 6 months to be included in the study.

\subsection{Statistical Analysis}

Descriptive statistics were performed using absolute and relative frequencies for qualitative variables and the mean, and standard deviation was used for quantitative variables. The level of statistical significance was at $p<0.05$. The statistical software used was SPSS v20.0 for Windows (SPSS Inc., Chicago, IL, USA), and Excel 14.0 software was also used (Microsoft Office 2011, Microsoft Corp, Albuquerque, New Mexico).

\section{Results}

Eight patients (eight eyes) with $\mathrm{MH}$ of different etiology were included. Four were MMH (50.0\%), two eyes were IMH (25.0\%), one was of iatrogenic origin $(12.5 \%)$, and one was traumatic $(12.5 \%)$. The overall mean age was $53.1 \pm 19.3(15.0-71.0)$ years, the mean age in men was $46.2 \pm 22.0$ (15.0-71.0) years, and for women was $64.7 \pm 3.1(62.0-68.0)$ years. Fifty per cent were right eyes, and $50 \%$ left eyes. Men correspond to $62.5 \%(n=5)$ and women to $37.5 \%(n=3)$. The time with the initial diagnosis of MH was as follows: overall mean of 19.9 months; for $\mathrm{MMH}$, it was 30.8 months; in IMH 13.5 months, in iatrogenic 
three months, and for the trauma, it was six months. Two eyes (25\%) previously had two surgeries with failure to close the $\mathrm{MH}$, four eyes (50\%) had one surgery without achieving $\mathrm{MH}$ closure, and two eyes (25\%) had not had previous surgeries (IMH, traumatic). Of those who had previous surgeries, $66.7 \%(n=4)$ had P-ILM. In all previously operated patients, the gas tamponade was $\mathrm{C} 3 \mathrm{~F} 8$. The mean time between reopening of the $\mathrm{MH}$ until the surgery using the PRGF is $16.6 \pm 20.7$ (1.6-63.0) months, where the longest time (63.0 months) corresponds to a case of $\mathrm{MMH}$ and the shortest time (1.6 months) was iatrogenic (Table 1). All eyes with MMH had previous unsuccessful surgeries with $\mathrm{MH}$ recurrence. The average time with a diagnosis of $\mathrm{MH}$ for this group was $30.8 \pm 29.2$ (3.0-72.0) months, and the mean time between MH recurrence until surgery with PRGF was $24.8 \pm 26.6(2.8-63.0)$ months.

Table 1. Baseline characteristics of patients with macular hole.

\begin{tabular}{|c|c|c|c|c|c|c|c|}
\hline $\begin{array}{l}\text { Num. Patient/Age } \\
\text { (Years)/Gender }\end{array}$ & $\begin{array}{l}\text { Laterality } \\
\text { (Eye) }\end{array}$ & $\begin{array}{l}\text { Primary Ophthalmologic } \\
\text { Disease }\end{array}$ & $\begin{array}{c}\text { MH } \\
\text { Etiology }\end{array}$ & $\begin{array}{l}\text { Time with Diagnosis } \\
\text { of MH (Months) }\end{array}$ & $\begin{array}{c}\text { Number of } \\
\text { Previous Surgeries }\end{array}$ & Detail of Previous Surgeries & $\begin{array}{l}\text { MH Time Open } \\
\text { Since Last Surgery } \\
\text { (Months) }\end{array}$ \\
\hline $1 / 36 / \mathrm{M}$ & $\mathrm{R}$ & $\mathrm{PDR}+\mathrm{VH}+\mathrm{SMH}$ & Iatrogenic & 3 & 1 & 1st: PPV + P-ILM + C3F8 & 1.6 \\
\hline $2 / 64 / \mathrm{F}$ & $\mathrm{L}$ & High myopia & MMH & 72 & 2 & 1st: PPV + TMHE + C3F8; 2nd: PPV + TMHE + C3F8 & 63 \\
\hline 3/47/M & $\mathrm{R}$ & High myopia & MMH & 3 & 1 & 1st: PPV + P-ILM + C3F8 & 2.8 \\
\hline $4 / 62 / \mathrm{M}$ & $\mathrm{L}$ & High myopia & MMH & 24 & 1 & 1st: PPV + P-ILM + C3F8 & 21.5 \\
\hline $5 / 71 / \mathrm{M}$ & $\mathrm{R}$ & Primary MH & IMH & 3 & 1 & 1st: PPV + P-ILM + C3F8 & 2 \\
\hline $6 / 68 / \mathrm{F}$ & $\mathrm{L}$ & Primary MH & IMH & 24 & 0 & N/A & 24 \\
\hline $7 / 62 / \mathrm{F}$ & $\mathrm{L}$ & High myopia & MMH & 24 & 2 & 1st: PPV + TMHE + C3F8; 2nd: PPV + TMHE + C3F8 & 12 \\
\hline $8 / 15 / \mathrm{M}$ & $\mathrm{R}$ & Traumatic MH & Trauma & 6 & 0 & N/A & 6 \\
\hline
\end{tabular}

M: Male, F: Female, R: Right, L: Left, MH: Macular Hole, MMH: Myopic Macular Hole, IMH: Idiopathic Macular Hole, PDR: Proliferative Diabetic Retinopathy, VH: Vitreous Hemorrhage, PPV: Pars Plana Vitrectomy, SMH: Subhyaloid Macular Hemorrhage, TMHE: Touch of Macular Hole Edges, P-ILM: Peeling of Internal Limiting Membrane, N/A: Not applicable.

For patient 1, when separating the hyaloid during the first PPV, strong adherence to the fovea was found, which when separated caused an iatrogenic MH. Patient 2 has a complete vision loss in the contralateral eye due to multiple atrophic myopic scars. Before surgery with PRGF, seventy-five per cent of eyes were pseudophakic $(n=6)$. The initial BCVA (logMAR) for the MMH group was $0.837 \pm 0.383(0.523-1.000)$ and the initial IOP was $13.3 \pm 1.3(12-15)$. In the OCT measurements, it was found that the overall mean of the base diameter was $1181.6 \pm 345.7(673.0-1577.0) \mu \mathrm{m}$, for the minimum diameter it was $516.9 \pm 154.7(313.0-806.0) \mu \mathrm{m}$, and for the height it was $462.8 \pm 58.1(380.0-519.0) \mu \mathrm{m}$. In the MMH group, these measurements were: base diameter 1049.5 $\pm 416.8(673.0-1470.0) \mu \mathrm{m}$, minimum diameter $531.5 \pm 229.6(313.0-806.0) \mu \mathrm{m}$, and height $454.0 \pm 59.3(389.0-511.0) \mu \mathrm{m}$. As for the surgeries performed on the four eyes that previously had P-ILM, two underwent only ILM rhexis and the other two rhexis plus ILM transposition into the MH. Hence, $37.5 \%(n=3)$ received iPRGF and $62.5 \%(n=5)$ received $\mathrm{m} /$ iPRGF (Table 2). Patients 3 and 5 needed to peel the epiretinal membrane (ERM) with which they had been associated. Patient 3 had the silicone oil removed at 3.7 months, leaving the final BCVA at 0.1 (decimal), having previously started with BCVA of 0.05 (decimal).

The overall post-surgical follow-up time was $27.2 \pm 9.01$ (12.5-35.8) months, and for the MMH group it was $21.1 \pm 8.84$ (12.5-31.0) months. The final state of the lens was $75 \%$ $(n=6)$ pseudophakic eyes, unchanged compared to the preoperative situation. Anatomical closure of the $\mathrm{MH}$ was obtained in seven cases $(87.5 \%)$. In one case of $\mathrm{IMH}$, there was no closure of $\mathrm{MH}$. However, a decrease in the anatomical measurements of the $\mathrm{MH}$ observed on the OCT was achieved (Table 2). Visual acuity improved in six cases (75\%). The MMH group improved on average two lines of vision, one eye with closed MMH kept the BCVA unchanged, and patient number 5 had no improvement in visual acuity, and no additional surgeries were performed on this patient (Figure 1). 
Table 2. Pre-surgical data and post-surgery results.

\begin{tabular}{|c|c|c|c|c|c|c|c|c|c|c|c|c|}
\hline Patient & $\begin{array}{l}\text { Pre-Surgery } \\
\text { Lens }\end{array}$ & $\begin{array}{c}\text { BCVA } \\
\text { Pre-Surgical; } \\
\text { Decimal } \\
\text { (LogMAR) }\end{array}$ & $\begin{array}{c}\text { IOP } \\
\begin{array}{c}\text { Pre-surgical } \\
\text { (mmHg) }\end{array}\end{array}$ & $\begin{array}{c}\text { Base } \\
\text { Diameter of } \\
\text { MH }(\mu \mathrm{m})\end{array}$ & $\begin{array}{l}\text { Minimum } \\
\text { Diameter of } \\
\text { MH }(\mu \mathrm{m})\end{array}$ & $\begin{array}{l}\text { Height of } \\
\text { MH }(\mu \mathrm{m})\end{array}$ & Surgery Performed & $\begin{array}{l}\text { Final State of the } \\
\text { Lens }\end{array}$ & $\begin{array}{l}\text { BCVA Final; } \\
\text { Decimal } \\
\text { (LogMAR) }\end{array}$ & $\begin{array}{c}\text { IOP } \\
\text { Final } \\
\text { (mmHg) }\end{array}$ & $\begin{array}{c}\text { Follow- } \\
\text { Up } \\
\text { Time } \\
\text { (Month) }\end{array}$ & $\begin{array}{l}\text { Final } \\
\text { Closure } \\
\text { of MH }\end{array}$ \\
\hline 1 & Phakic & $0.2(0.699)$ & 14 & 1031 & 433 & 514 & PPV + rexis ILM + TMHE + iPRGF + C3F8 & Phakic & $0.6(0.222)$ & 14 & 29 & $\mathrm{Si}$ \\
\hline 2 & Pseudophakic & $0.3(0.523)$ & 15 & 673 & 313 & 389 & $\mathrm{PPV}+\mathrm{TMHE}+\mathrm{iPRGF}+\mathrm{C} 3 \mathrm{~F} 8$ & Pseudophakic & $0.6(0.222)$ & 11 & 25.9 & $\mathrm{Si}$ \\
\hline 3 & Pseudophakic & $0.05(1.301)$ & 12 & 1345 & 806 & 497 & $\mathrm{PPV}+\mathrm{R}$ and $\mathrm{T}$ ILM $+\mathrm{m} / \mathrm{iPRGF}+$ SilOil & Pseudophakic & $0.1(1.000)$ & 15 & 12.5 & $\mathrm{Si}$ \\
\hline 4 & Pseudophakic & $0.1(1.000)$ & 13 & 1470 & 633 & 511 & $\mathrm{PPV}+$ rexis ILM $+\mathrm{TMHE}+\mathrm{m} / \mathrm{iPRGF}+\mathrm{C} 3 \mathrm{~F} 8$ & Pseudophakic & $0.1(1.000)$ & 12 & 14.8 & $\mathrm{Si}$ \\
\hline 5 & Pseudophakic & $0.1(1.000)$ & 13 & 1577 & 499 & 473 & $\mathrm{PPV}+\mathrm{R}$ and $\mathrm{T} \mathrm{ILM}+\mathrm{m} / \mathrm{iPRGF}+\mathrm{C} 3 \mathrm{~F} 8$ & Pseudophakic & $0.01(2.000)$ & 9 & 33.3 & No + \\
\hline 6 & Pseudophakic & $0.4(0.398)$ & 15 & 1209 & 547 & 519 & $\mathrm{PPV}+\mathrm{P}-\mathrm{ILM}+\mathrm{m} / \mathrm{iPRGF}+\mathrm{C} 3 \mathrm{~F} 8$ & Pseudophakic & $1.0(0.000)$ & 15 & 35.5 & $\mathrm{Si}$ \\
\hline 7 & Pseudophakic & $0.3(0.523)$ & 13 & 710 & 374 & 419 & $\mathrm{PPV}+\mathrm{TMHE}+\mathrm{iPRGF}+\mathrm{C} 3 \mathrm{~F} 8$ & Pseudophakic & $0.5(0.301)$ & 12 & 31 & $\mathrm{Si}$ \\
\hline 8 & Phakic & $0.05(1.301)$ & 17 & 1438 & 530 & 380 & $\mathrm{PPV}+\mathrm{P}-\mathrm{ILM}+\mathrm{m} / \mathrm{iPRGF}+\mathrm{C} 3 \mathrm{~F} 8$ & Phakic & $0.6(0.222)$ & 13 & 35.8 & $\mathrm{Si}$ \\
\hline
\end{tabular}

BCVA: Best Corrected Visual Acuity, IOP: intraocular pressure, MH: Macular Hole, PPV: Pars Plana Vitrectomy, ILM: Internal Limiting Membrane, TMHE: Touch of Macular Hole Edges, iPRGF: Plasma Rich in Growth Factors in injectable liquid form, P-ILM: Peeling of Internal Limiting Membrane, R and T ILM: Rexis and transposition of internal limiting me brane Oil, ERM: Epiretinal membrane, + Macular hole not closed (remains with opening base diameter: $960 \mu \mathrm{m}$, minimum diameter: $490 \mu \mathrm{m}$ and height: $364 \mu \mathrm{m}$ ) 


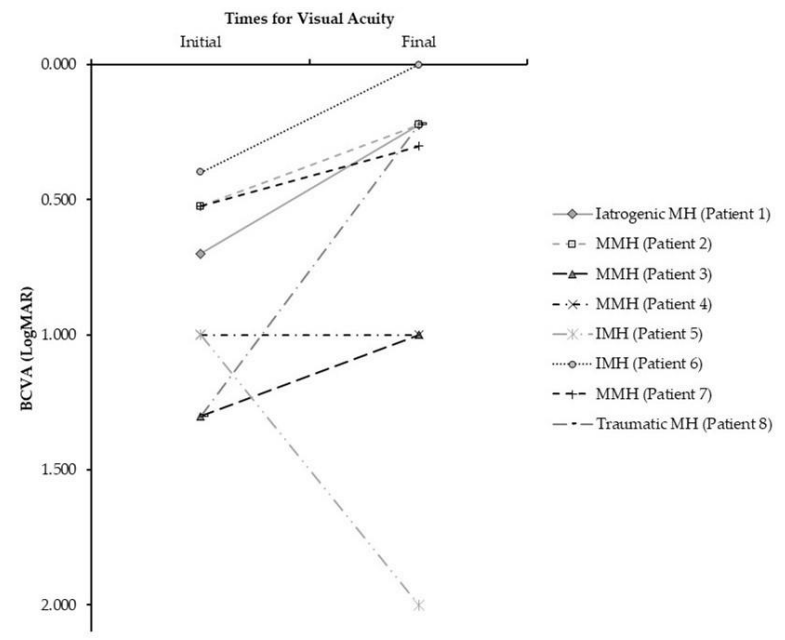

Figure 1. Result in visual acuity due to the use of PRGF in macular hole surgery. Description of changes in visual acuity according to the type of macular hole. PRGF: Plasma Rich in Growth Factors, BCVA: Best Corrected Visual Acuity, MMH: Myopic Macular Hole, IMH: Idiopathic Macular Hole.

The BCVA of the patient with iatrogenic MH improved four lines of visual acuity. Patient number 6 with IMH obtained anatomical closure, and the final BCVA was 1.0 decimal with improvement of four lines of visual acuity. In traumatic MH, the BCVA improved in six lines of visual acuity. Figures 2-4 illustrate the anatomical results of patients with $\mathrm{MH}$ of different etiology undergoing PPV and the use of PRGF as an adjuvant. Figure 2 corresponds to patient 2 with MMH, Figure 3 illustrates the evolution of patient 6, who has an IMH, and Figure 4 represents the anatomical changes of the traumatic MH of patient number 8 . During the follow-up time, no adverse events related to the given therapy were recorded.

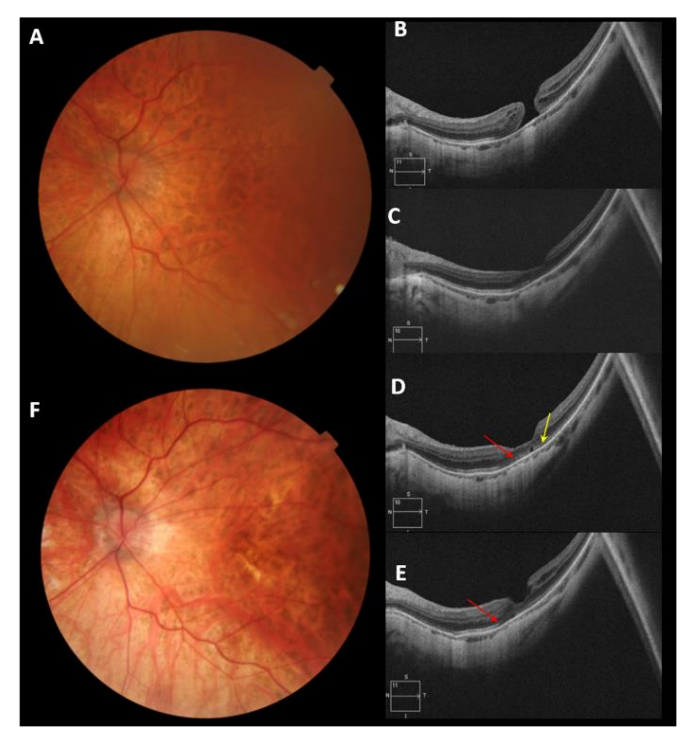

Figure 2. Patient number 2 diagnosed with recurrent $\mathrm{MMH}$ (myopic macular hole) with two previous failed PPV (Pars Plana Vitrectomy). (A) Retinography of recurrent MMH with 63 months of evolution, before surgery with Plasma Rich in Growth Factors liquid injection (iPRGF). (B)Pre-surgical optical coherence tomography (OCT) of MMH. (C) OCT macular image one month after surgery. (D) OCT at six months follow-up, restoration of the (ELM) External Limiting Membrane (red arrow) and the ellipsoid layer (yellow arrow) is observed, leaving a small cyst at the central foveal level. (E) OCT at twelve months of follow-up, the formation of the ELM (red arrow) is observed. (F) Retinography at the end of follow-up (29.5 months). 


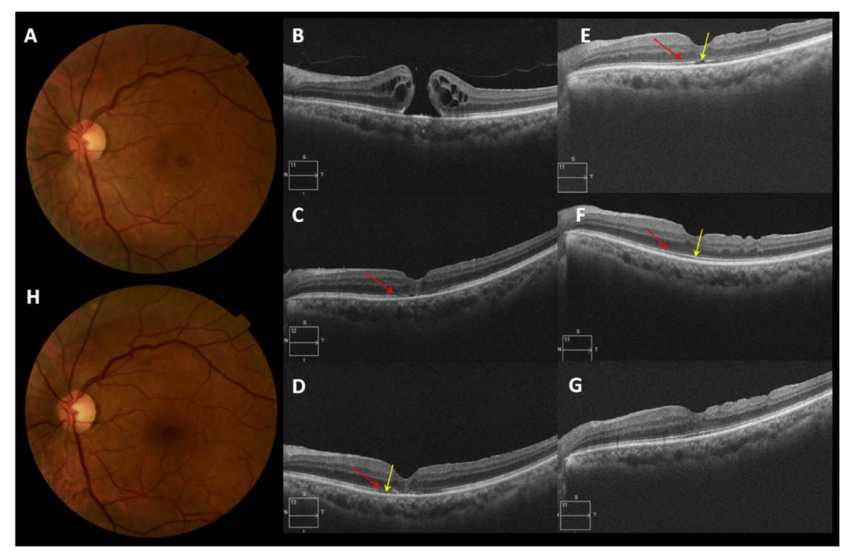

Figure 3. Patient number 6 diagnosed with a large idiopathic macular hole (IMH) without prior PPV (Pars Plana Vitrectomy). (A) Presurgical retinography of IMH in Gass stage 4 and $>400 \mu \mathrm{m}$ minimum diameter. (B) The initial optical coherence tomography (OCT) image shows a large IMH with multiple cystic spaces. (C) Image of macular OCT one month after surgery (injectable liquid and membrane PRGF were used as an adjuvant to PPV) shows the closed IMH and the start of the formation of ELM (External Limiting Membrane) (red arrow). (D) OCT two months post-surgery shows the formation of the ELM (red arrow) and initiates restoration of the ellipsoid layer (yellow arrow). (E) OCT seven months post-surgery shows the complete formation of the ELM (red arrow) at the foveal level with a lack of continuity in the ellipsoid layer (yellow arrow). (F) OCT 24 months post-surgery, the complete formation of the ELM (red arrow) and ellipsoid layer (yellow arrow) is observed. (G) OCT 35.5 months post-surgery, patient with final BCVA of 1.0 decimal (0.000 LogMar). (H) Retinography at the end of follow-up: no clinical evidence of IMH.

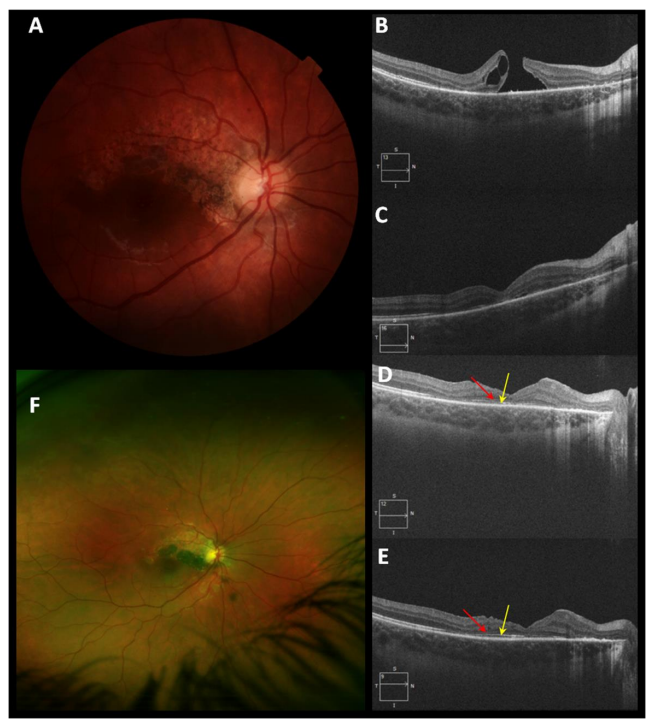

Figure 4. Patient number 8 with a Diagnosis of traumatic macular hole (TMH). (A) Retinography that shows chronic changes in the TMH of six months of evolution, no surgery has been performed. (B) Optical coherence tomography pre-surgical OCT. The initial BCVA (Best Corrected Visual Acuity) was 0.05 decimal (1301 LogMar), injectable liquid and PRGF membrane are used as adjuvants in PPV (Pars Plana Vitrectomy). (C) OCT one month after surgery. TMH closure observed. (D) OCT three months post-surgical. The segmented restoration of the External Limiting Membrane (ELM) (red arrow) and of the ellipsoid layer (yellow arrow) is observed. (E) OCT image at twelve months post-surgical follow-up, thinning of the inner layers of the retina is observed, the restoration of the ELM (red arrow) and the ellipsoid layer (yellow arrow) is maintained. (F) Fundus photography taken with Optomap at 35.8 months of follow-up, TMH closure is maintained, and BVCA is recovered at 0.6 decimal (0.222 LogMar). 


\section{Discussion}

It is known that the anatomical closure rate of the medium-sized MH $(250-400 \mu \mathrm{m})$, at which PPV is performed associated or not with ILM peeling, is greater than $90 \%[9,25]$. However, for large MHs (>400 $\mu \mathrm{m})$, the closing rates can be around 75\% [27]. In many cases, this anatomical closure is not accompanied by improvement in visual acuity.

The standard treatment for MH is PPV, posterior hyaloid removal, with/without ILM peeling, long-lasting gas tamponade, and face-down position. However, in large, myopic, chronic, or recurrent HMs, the treatment is more diverse and changes rapidly [2]. In MMH treatment, the P-ILM is controversial since this procedure may increase the risk of damage to the retinal nerve fibre layer-ganglion cell complex [28]. Different methods have been used to increase the MH closure rate, such as inverted ILM flap, inverted ILM flap insertion, multiple free ILM flap insertion, posterior lens capsule, relaxing retinotomies, including autologous neurosensory retinal flaps [29-32]. With these techniques, different clinical results are achieved. Some authors have described retinal fibrosis and dystrophy of the RPE in the macular area after autologous transplantation of ILM, which would be related to the non-recovery of visual acuity [33]. A technique described in the treatment of MMH is the macular buckling that is used in recurrent cases, with a success rate in anatomical closure between $70 \%$ and $100 \%$ according to published series [2]. However, the surgeon must be highly skilled in positioning the buckle correctly and perform the posterior suture.

Since the 1990s, blood derivatives (autologous serum, autologous platelet concentrates (APC) or also called platelet rich plasma (PRP)) have been used classically as an adjuvant therapy to increase the rate of closure in MHs [14,34]. More recently, biological tissues have been used as scaffolding with the ability to release growth factors, including human amniotic membrane (hAM) [35], fibrin rich plasma [36], and PRGF [23,37].

In a case series, the use of autologous serum as a chorioretinal adhesive associated with PPV and subsequent hyaloid release was evaluated in 44 patients with IMH of all stages. The average visual recovery was 2.7 lines, and MH closure occurred in $67 \%$ of cases [14]. In a clinical trial comparing the use of APC versus control as adjuvant therapy to PPV in patients with chronic IMH (stages 3 and 4), IMH closure was observed in $98 \%$ vs. $82 \%(p=0.009)$. However, visual acuity did not improve [24]. Differences between autologous serum and APC have been studied in an animal model of $\mathrm{MH}$, where a higher proliferation rate in cells of the outer nuclear layer was evidenced in the group treated with APC [37]. In a retrospective case series, APC was used as adjuvant therapy for PPV in patients with chronic IMH ( $>24$ months) unable to adopt the prone position after surgery. MH closure was observed in 100\% during follow-up (1-6 months), and 38\% of patients reported improvement in visual acuity [38]. On the other hand, in traumatic $\mathrm{MH}$, it is known that there is a waiting period between three and four months in which spontaneous anatomical closure can be achieved, particularly in holes of 100 to $200 \mu \mathrm{m}$. However, in large traumatic MH, surgery is necessary (PPV with or without P-ILM) to achieving a closure success rate between $67 \%$ and $85 \%$ [39]. In a series of cases of four pediatric patients (10-15 years old) who had a traumatic MH stage 3 Gass (1 to 5 months of evolution), PPV associated with adjuvant treatment with APC was performed, achieving MH closure in all cases and improving between three and seven lines of vision [40].

In patients with recurrent IMH, the use of APC is effective in closing MH. In a retrospective study that included 61 eyes, MH closure was achieved in $85.2 \%$ of cases. However, it can be determined that patients with a defect in the ellipsoid area had worse postoperative visual acuity [41]. In another study that included 29 patients with recurrent IMH, PPV with P-ILM and gas tamponade without adjuvant therapy was performed, and MH closure was achieved in only $69 \%$ of cases [42].

In patients with $\mathrm{MMH}, \mathrm{MH}$ closure is less effective with the standard surgical technique, the closure rate can vary between 62.5 and 87.5 according to the different published series, and the need for additional surgeries is much higher $[10,11]$. However, in a study that included seven eyes with $\mathrm{MMH}$, using an autologous platelet-rich plasma with the open technique [11], MH closure was achieved in all cases and improved one line of visual 
acuity in three of the seven cases, with a mean follow-up of 5.8 months. In cases with recurrent $\mathrm{MH}$ in which P-ILM has already been performed and in a second PPV, it is impossible to extend the rhexis. One option is to touch the edges of the MH trying to introduce the glial tissue into the MH and to use APC as adjuvant treatment [43]. In a study with $27 \mathrm{MMH}$ patients, the autologous blood clot associated with MLI replacement was evaluated to repair MH retinal detachment; anatomical closure was obtained in $96 \%$ of cases with follow-up of only $12.4 \pm 5.3$ months [44]. In our study, the follow-up was $27.2 \pm 9.0$ months, and anatomical closure was achieved in $87.5 \%$ of the cases in patients with previous vitrectomy and poor visual prognosis.

The use of the hAM as a plug in the subretinal space for the treatment of recurrent IMH has recently been published. In all eight cases evaluated, MH closure was achieved in all, improving from a mean initial BCVA of 1488 (LogMAR) to a mean final BCVA of 0.480 (LogMAR). Restoration of the outer retinal layers was also observed, with growth over the hAM plug (evaluated by OCT), which would be related to the improvement of visual acuity [35]. In this series of patients, standard tamponade gas or silicone oil was used at the end of the surgery. This suggests the need for tissue scaffolding to achieve good retinal tissue restoration.

PRGF is a select type of PRP that uses a standardized procedure called Endoret ${ }^{\circledR}$ $-\mathrm{PRGF}^{\circledR}[16,17]$. Among the characteristics of the PRGF are its closed manufacturing technique, the quality marking by the European Medicines Agency (EMA), the patented platelet activation, the product versatility (injectable liquid, eye drops, clot, membrane), rapid manufacturing (in less than $60 \mathrm{~min}$ ), the possibility of preparing it in the same surgery room, a concentration of growth factors higher than other blood derivatives, the absence of leukocytes, the inactivation of inflammatory products (complement cascade), and decreased levels of IgE $[18,26]$. The clinical efficacy of PRGF has been proven in ophthalmological pathologies (dry eye, neurotrophic corneal ulcers, surgical use in the conjunctiva and cornea, among others), with pre-clinical evidence supporting the proliferation, migration, and restoration of ocular tissues [19-21]. Particularly in MH surgery, two studies have already been published. The first was a case of recurrent MMH with $700 \mu \mathrm{m}$ (minimum diameter) in which PPV was performed with mPRGF and a six-month follow-up, observing the closure of the $\mathrm{MH}$ and visual recovery of counting fingers to 0.1 (decimal) [23]. In the other study, two cases with persistent IMH with sizes of $691 \mu \mathrm{m}$ and $1020 \mu \mathrm{m}$ were evaluated, in which PPV was performed associated with mPRGF and iPRG. The closure of $\mathrm{MH}$ was observed in the two cases (12 months follow-up) and with visual acuity improvement (case 1:1 to 0.69 (LogMAR), case 2:1.8 to 0.64 (LogMar)) [45].

Our study evaluated the anatomical and functional outcome of mPRGF and iPRGF as an adjuvant to PPV in patients with recurrent, persistent or with poor prognosis $\mathrm{MH}$ of various etiologies. Anatomical closure was observed in seven cases $(87.5 \%)$, and visual acuity improvement in six cases, particularly in the MMH group, which improved two lines of vision. The most frequent cases were MMH $(n=4.50 \%)$, followed by $\operatorname{IMH}(n=2.25 \%)$, one case of idiopathic $\mathrm{MH}$, and one traumatic. The $\mathrm{MMH}$ patients were also chronic since they had an average of more than 24 months until the new surgery with PRGF. In one case, $\mathrm{MH}$ closure was not obtained, perhaps due to its large size $(1577 \mu \mathrm{m})$. If the first surgery had involved the use of mPRGF plus iPRGF as adjuvant therapy, it is possible that closure of the macular hole would have been achieved. No adverse events were recorded with PRGF, and the overall follow-up time was long (27.2 months on average), which shows clinical stability and no reopening of HM. The use of mPRGF as scaffolding for the restoration of retinal tissue, associated with iPRGF with the gradual release of growth factors, can be a great therapeutic option since the regeneration of the outer layers is evidenced in this study.

The PRGF contains among its molecules PDGF (platelet-derived growth factor), TGF$\beta$ (transforming growth factor- $\beta$ ), FGF (fibroblast growth factor), EGF (epidermal growth factor), IGF (insulin-like growth factor), NGF (nerve growth factor), and other growth factors, which are involved in cell proliferation, modulation of inflammation and tissue restoration [16,17]. On the other hand, the mPRGF provides a sustained release of growth 
factors and has mechanical properties that allow its use in surgery $[21,46,47]$. At the same time, the efficacy of the use of mPRGF as scaffolding has been seen in research models of advanced therapies in cell expansion [48]. The mechanisms involved in the closure of $\mathrm{MH}$ when using PRGF include trophic action of growth factors [23,49] as well as Müller cell migration and concentration [11]. Moreover, mPRGF allows the sustained release of growth factors, promotes glial growth (not fibrosis) $[35,45,50]$, and modulates the antioxidant response in the RPE [51].

There are some disadvantages in the manufacturing of ACP or PRPs, such as open production, which requires the use of a laminar flow hood, the availability of a hematology service for the elaboration of the products, and some of these products may most likely contain leukocytes, which increases the inflammatory response. Moreover, such use as part of a non-standardized manufacturing technique limits clinical predictability [17]. In the case of the hAM, it requires the availability of a tissue bank and highly specialized personnel for production, which increases the associated costs.

In this study, the use of PRGF as adjuvant therapy for vitrectomy in MHs of different etiologies (IMH, MMH, iatrogenic and traumatic) with poor prognosis, persistent or recurrent, has been evaluated. This autologous biological approach may be a new tool that can be added to standard surgical techniques in macular surgery. Our study has some limitations, such as being retrospective, not comparative, of different $\mathrm{MH}$ etiologies, and with a small sample. However, it opens the door to the design of future clinical trials in which the findings reported in this publication can be more strongly confirmed. Our study reinforces the hypothesis of the concept of PRGF-mediated retinal regeneration, in which pre-clinical and clinical research should be further expanded.

\section{Conclusions}

In the patients of this pilot study, efficacy was observed in closing the $\mathrm{MH}$ and improving visual acuity. This publication could open the door to the use of PRGF as an adjuvant therapy in the surgery of recurrent, persistent, or poor prognosis $\mathrm{MH}$. These findings need to be confirmed with further comparative studies.

Author Contributions: Conceptualization, R.M.S.-Á., E.V.-D., Á.F.-V.S. and J.M.-L.; methodology, R.M.S.-Á., E.V.-D. and Á.F.-V.S.; software, R.M.S.-Á. and C.A.R.-E.; validation, R.M.S.-Á., C.A.R.-E. and Á.F.-V.S.; formal analysis, R.M.S.-Á. and C.A.R.-E.; investigation, R.M.S.-Á., Á.F.-V.S. and Á.F.-V.G.; resources, Á.F.-V.S.; data curation, R.M.S.-Á. and C.A.R.-E.; writing—original draft preparation, R.M.S.-Á., C.A.R.-E. and J.M.-L.; writing—review and editing, R.M.S.-Á., C.A.R.-E., E.V.-D., Á.F.-V.S., Á.F.-V.G., B.d.I.S.-C. and J.M.-L.; visualization, R.M.S.-Á., B.d.I.S.-C. and J.M.-L.; supervision, J.M.-L.; project administration, R.M.S.-Á. and Á.F.-V.S.; funding acquisition, Á.F.-V.S., J.M.-L. and E.A. All authors have read and agreed to the published version of the manuscript.

Funding: This research received no external funding.

Institutional Review Board Statement: As the study was retrospective, the Institutional Board decided that we did not need an ethical approval number. The study was conducted according to the guidelines of the Declaration of Helsinki.

Informed Consent Statement: The patients signed the informed consent to receive the treatments of this clinical study.

Data Availability Statement: All data were fully anonymized and are available upon request.

Acknowledgments: The authors thank Virginia Cuadrado for her support with the English grammar.

Conflicts of Interest: The authors declare the following conflicts of interest: E.A., is the Scientific Director, R.M.S.-Á. and B.d.I.S.-C. are scientists at BTI Biotechnology Institute, a company that investigates in the fields of oral implantology and PRGF-Endoret technology. The other authors declare no conflict of interest in developing this study. 


\section{References}

1. Bikbova, G.; Oshitari, T.; Baba, T.; Yamamoto, S.; Mori, K. Pathogenesis and Management of Macular Hole: Review of Current Advances. J. Ophthalmol. 2019, 2019, 3467381. [CrossRef] [PubMed]

2. De Giacinto, C.; Pastore, M.R.; Cirigliano, G.; Tognetto, D.; Azzolini, C. Macular Hole in Myopic Eyes: A Narrative Review of the Current Surgical Techniques. J. Ophthalmol. 2019, 2019, 3230695. [CrossRef]

3. Tam, A.L.C.; Yan, P.; Gan, N.Y.; Lam, W.-C. The current surgical management of large, recurrent, or persistent macular holes. Retina 2018, 38, 1263-1275. [CrossRef] [PubMed]

4. Chung, H.; Byeon, S.H. New insights into the pathoanatomy of macular holes based on features of optical coherence tomography. Surv. Ophthalmol. 2017, 62, 506-521. [CrossRef]

5. Sheidow, T.G.; Blinder, K.J.; Holekamp, N.; Joseph, D.; Shah, G.; Grand, M.G.; Thomas, M.A.; Bakal, J.; Sharma, S. Outcome results in macular hole surgery: An evaluation of internal limiting membrane peeling with and without indocyanine green. Ophthalmology 2003, 110, 1697-1701. [CrossRef]

6. Dai, Y.; Dong, F.; Zhang, X.; Yang, Z. Internal limiting membrane transplantation for unclosed and large macular holes. Graefe's Arch. Clin. Exp. Ophthalmol. 2016, 254, 2095-2099. [CrossRef]

7. Wrzesińska, D.; Nowomiejska, K.; Nowakowska, D.; Toro, M.D.; Bonfiglio, V.; Reibaldi, M.; Avitabile, T.; Rejdak, R. Secondary Vitrectomy with Internal Limiting Membrane Plug due to Persistent Full-Thickness Macular Hole OCT-Angiography and Microperimetry Features: Case Series. J. Ophthalmol. 2020, 2020, 2650873. [CrossRef]

8. Morizane, Y.; Shiraga, F.; Kimura, S.; Hosokawa, M.; Shiode, Y.; Kawata, T.; Hosogi, M.; Shirakata, Y.; Okanouchi, T. Autologous transplantation of the internal limiting membrane for refractory macular holes. Am. J. Ophthalmol. 2014, 157, 861-869.e1. [CrossRef]

9. Ip, M.S.; Baker, B.J.; Duker, J.S.; Reichel, E.; Baumal, C.R.; Gangnon, R.; Puliafito, C.A. Anatomical outcomes of surgery for idiopathic macular hole as determined by optical coherence tomography. Arch. Ophthalmol. 2002, 120, 29-35. [CrossRef]

10. Alkabes, M.; Pichi, F.; Nucci, P.; Massaro, D.; Dutra Medeiros, M.; Corcostegui, B.; Mateo, C. Anatomical and visual outcomes in high myopic macular hole (HM-MH) without retinal detachment: A review. Graefes Arch. Clin. Exp. Ophthalmol. 2014, 252, 191-199. [CrossRef]

11. Figueroa, M.S.; Govetto, A.; Arriba-Palomero, P. Short-term results of platelet-rich plasma as adjuvant to 23-G vitrectomy in the treatment of high myopic macular holes. Eur. J. Ophthalmol. 2016, 26, 491-496. [CrossRef] [PubMed]

12. Smiddy, W.E.; Glaser, B.M.; Green, W.R.; Connor, T.B.J.; Roberts, A.B.; Lucas, R.; Sporn, M.B. Transforming growth factor beta. A biologic chorioretinal glue. Arch. Ophthalmol. 1989, 107, 577-580. [CrossRef]

13. Olsen, T.W.; Sternberg, P.J.; Capone, A.J.; Martin, D.F.; Lim, J.I.; Grossniklaus, H.E.; Aaberg, T.M.S. Macular hole surgery using thrombin-activated fibrinogen and selective removal of the internal limiting membrane. Retina 1998, 18, 322-329. [CrossRef] [PubMed]

14. Wells, J.A.; Gregor, Z.J. Surgical treatment of full-thickness macular holes using autologous serum. Eye 1996, 10, 593-599. [CrossRef] [PubMed]

15. Vote, B.J.; Membrey, W.L.; Casswell, A.G. Autologous platelets for macular hole surgery: The Sussex Eye Hospital experience. Clin. Exp. Ophthalmol. 2004, 32, 472-477. [CrossRef]

16. Anitua, E.; Muruzabal, F.; Tayebba, A.; Riestra, A.; Perez, V.L.; Merayo-Lloves, J.; Orive, G. Autologous serum and plasma rich in growth factors in ophthalmology: Preclinical and clinical studies. Acta Ophthalmol. 2015, 93, e605-e614. [CrossRef]

17. Riestra, A.C.; Alonso-Herreros, J.M.; Merayo-Lloves, J. Plasma rico en plaquetas en superficie ocular. Arch. Soc. Esp. Oftalmol. 2016, 91, 475-490. [CrossRef]

18. Anitua, E.; de la Fuente, M.; Riestra, A.; Merayo-Lloves, J.; Muruzábal, F.; Orive, G. Preservation of Biological Activity of Plasma and Platelet-Derived Eye Drops After Their Different Time and Temperature Conditions of Storage. Cornea 2015, 34, 1144-1148. [CrossRef]

19. Sanchez-Avila, R.M.; Merayo-Lloves, J.; Riestra, A.C.; Anitua, E.; Muruzabal, F.; Orive, G.; Fernandez-Vega, L. The Effect of Immunologically Safe Plasma Rich in Growth Factor Eye Drops in Patients with Sjogren Syndrome. J. Ocul. Pharmacol. Ther. 2017, 33, 391-399. [CrossRef] [PubMed]

20. Sanchez-Avila, R.M.; Merayo-Lloves, J.; Riestra, A.C.; Fernandez-Vega Cueto, L.; Anitua, E.; Begona, L.; Muruzabal, F.; Orive, G. Treatment of patients with neurotrophic keratitis stages 2 and 3 with plasma rich in growth factors (PRGF-Endoret) eye-drops. Int. Ophthalmol. 2018, 38, 1193-1204. [CrossRef]

21. Sanchez-Avila, R.M.; Merayo-Lloves, J.; Riestra, A.C.; Berisa, S.; Lisa, C.; Sanchez, J.A.; Muruzabal, F.; Orive, G.; Anitua, E. Plasma rich in growth factors membrane as coadjuvant treatment in the surgery of ocular surface disorders. Medicine 2018, 97 , e0242. [CrossRef]

22. Sánchez-Avila, R.M.; Merayo-Lloves, J.; Fernández, M.L.; Rodríguez-Gutiérrez, L.A.; Rodríguez-Calvo, P.P.; Fernández-Vega Cueto, A.; Muruzabal, F.; Orive, G.; Anitua, E. Plasma rich in growth factors eye drops to treat secondary ocular surface disorders in patients with glaucoma. Int. Med. Case Rep. J. 2018, 11, 97-103. [CrossRef]

23. Sanchez-Avila, R.M.; Fernandez-Vega Gonzalez, A.; Fernandez-Vega Sanz, A.; Merayo-Lloves, J. Treatment of recurrent myopic macular hole using membrane of plasma rich in growth factors. Int. Med. Case Rep. J. 2019, 12, 229-233. [CrossRef] 
24. Paques, M.; Chastang, C.; Mathis, A.; Sahel, J.; Massin, P.; Dosquet, C.; Korobelnik, J.F.; Le Gargasson, J.F.; Gaudric, A. Effect of autologous platelet concentrate in surgery for idiopathic macular hole: Results of a multicenter, double-masked, randomized trial. Platelets in Macular Hole Surgery Group. Ophthalmology 1999, 106, 932-938. [CrossRef]

25. Duker, J.S.; Kaiser, P.K.; Binder, S.; de Smet, M.D.; Gaudric, A.; Reichel, E.; Sadda, S.R.; Sebag, J.; Spaide, R.F.; Stalmans, P. The International Vitreomacular Traction Study Group classification of vitreomacular adhesion, traction, and macular hole. Ophthalmology 2013, 120, 2611-2619. [CrossRef]

26. Anitua, E.; Muruzabal, F.; De la Fuente, M.; Merayo-Lloves, J.; Orive, G. Effects of heat-treatment on plasma rich in growth factors-derived autologous eye drop. Exp. Eye Res. 2014, 119, 27-34. [CrossRef] [PubMed]

27. Ullrich, S.; Haritoglou, C.; Gass, C.; Schaumberger, M.; Ulbig, M.W.; Kampik, A. Macular hole size as a prognostic factor in macular hole surgery. Br. J. Ophthalmol. 2002, 86, 390-393. [CrossRef] [PubMed]

28. Mete, M.; Alfano, A.; Guerriero, M.; Prigione, G.; Sartore, M.; Polito, A.; Pertile, G. Inverted internal limiting membrane flap technique versus complete internal limiting membrane removal in myopic macular hole surgery: A Comparative Study. Retina 2017, 37, 1923-1930. [CrossRef]

29. Kuriyama, S.; Hayashi, H.; Jingami, Y.; Kuramoto, N.; Akita, J.; Matsumoto, M. Efficacy of inverted internal limiting membrane flap technique for the treatment of macular hole in high myopia. Am. J. Ophthalmol. 2013, 156, 125-131.e1. [CrossRef]

30. Chen, S.-N.; Yang, C.-M. Inverted Internal Limiting Membrane Insertion for Macular Hole-Associated Retinal Detachment in High Myopia. Am. J. Ophthalmol. 2016, 162, 99-106.e1. [CrossRef]

31. Chen, S.-N.; Hsieh, Y.-T.; Yang, C.-M. Multiple Free Internal Limiting Membrane Flap Insertion in the Treatment of Macular Hole-Associated Retinal Detachment in High Myopia. Ophthalmologica 2018, 240, 143-149. [CrossRef]

32. Ding, C.; Li, S.; Zeng, J. Autologous Neurosensory Retinal Transplantation for Unclosed and Large Macular Holes. Ophthalmic Res. 2019, 61, 88-93. [CrossRef]

33. Lee, S.M.; Kwon, H.J.; Park, S.W.; Lee, J.E.; Byon, I.S. Microstructural changes in the fovea following autologous internal limiting membrane transplantation surgery for large macular holes. Acta Ophthalmol. 2018, 96, e406-e408. [CrossRef] [PubMed]

34. Korobelnik, J.F.; Hannouche, D.; Belayachi, N.; Branger, M.; Guez, J.E.; Hoang-Xuan, T. Autologous platelet concentrate as an adjunct in macular hole healing: A pilot study. Ophthalmology 1996, 103, 590-594. [CrossRef]

35. Rizzo, S.; Caporossi, T.; Tartaro, R.; Finocchio, L.; Franco, F.; Barca, F.; Giansanti, F. A Human Amniotic Membrane Plug to Promote Retinal Breaks Repair and Recurrent Macular Hole Closure. Retina 2019, 39, S95-S103. [CrossRef]

36. Koytak, A.; Nuhoglu, F.; Bayraktar, H.; Ercan, R.; Ozdemir, H. Autologous Platelet-Rich Fibrin in the Treatment of Refractory Macular Holes. Case Rep. Ophthalmol. Med. 2019, 2019, 6054215. [CrossRef]

37. Cullinane, A.B.; O'Callaghan, P.; McDermo tt, K.; Keohane, C.; Cleary, P.E. Effects of autologous platelet concentrate and serum on retinal wound healing in an animal model. Graefes Arch. Clin. Exp. Ophthalmol. 2002, 240, 35-41. [CrossRef]

38. Kapoor, K.G.; Khan, A.N.; Tieu, B.C.; Khurshid, G.S. Revisiting autologous platelets as an adjuvant in macular hole repair: Chronic macular holes without prone positioning. Ophthalmic Surg. Lasers Imaging Off. J. Int. Soc. Imaging Eye 2012, 43, $291-295$. [CrossRef] [PubMed]

39. Johnson, R.N.; McDonald, H.R.; Lewis, H.; Grand, M.G.; Murray, T.G.; Mieler, W.F.; Johnson, M.W.; Boldt, H.C.; Olsen, K.R.; Tornambe, P.E.; et al. Traumatic macular hole: Observations, pathogenesis, and results of vitrectomy surgery. Ophthalmology 2001, 108, 853-857. [CrossRef]

40. Wachtlin, J.; Jandeck, C.; Potthofer, S.; Kellner, U.; Foerster, M.H. Long-term results following pars plana vitrectomy with platelet concentrate in pediatric patients with traumatic macular hole. Am. J. Ophthalmol. 2003, 136, 197-199. [CrossRef]

41. Purtskhvanidze, K.; Frühsorger, B.; Bartsch, S.; Hedderich, J.; Roider, J.; Treumer, F. Persistent Full-Thickness Idiopathic Macular Hole: Anatomical and Functional Outcome of Revitrectomy with Autologous Platelet Concentrate or Autologous Whole Blood. Ophthalmologica 2017, 239, 19-26. [CrossRef]

42. D'Souza, M.J.J.; Chaudhary, V.; Devenyi, R.; Kertes, P.J.; Lam, W.-C. Re-operation of idiopathic full-thickness macular holes after initial surgery with internal limiting membrane peel. Br. J. Ophthalmol. 2011, 95, 1564-1567. [CrossRef] [PubMed]

43. Kim, J.Y.; Kwon, O.W. Vitrectomy for Refractory Macular Hole. Retin Cases Br. Rep. 2015, 9, 265-268. [CrossRef] [PubMed]

44. Lai, C.C.; Chen, Y.P.; Wang, N.K.; Chuang, L.H.; Liu, L.; Chen, K.J.; Hwang, Y.S.; Wu, W.C.; Chen, T.L. Vitrectomy with Internal Limiting Membrane Repositioning and Autologous Blood for Macular Hole Retinal Detachment in Highly Myopic Eyes. Ophthalmology 2015, 122, 1889-1898. [CrossRef] [PubMed]

45. Arias, J.D.; Hoyos, A.T.; Alcántara, B.; Sanchez-avila, R.M.; Arango, F.J.; Galvis, V. Plasma rich in growth factors for persistent macular hole: A pilot study. Retin. Cases Brief Rep. 2019. [CrossRef]

46. Anitua, E.; Prado, R.; Azkargorta, M.; Rodriguez-Suarez, E.; Iloro, I.; Casado-Vela, J.; Elortza, F.; Orive, G. High-throughput proteomic characterization of plasma rich in growth factors (PRGF-Endoret)-derived fibrin clot interactome. J. Tissue Eng. Regen. Med. 2015, 9, E1-E12. [CrossRef]

47. Anitua, E.; Nurden, P.; Prado, R.; Nurden, A.T.; Padilla, S. Autologous fibrin scaffolds: When platelet- and plasma-derived biomolecules meet fibrin. Biomaterials 2019, 192, 440-460. [CrossRef]

48. Riestra, A.C.; Vazquez, N.; Chacon, M.; Berisa, S.; Sanchez-Avila, R.M.; Orive, G.; Anitua, E.; Meana, A.; Merayo-Lloves, J. Autologous method for ex vivo expansion of human limbal epithelial progenitor cells based on plasma rich in growth factors technology. Ocul. Surf. 2017, 15, 248-256. [CrossRef] 
49. Hoerauf, H.; Klüter, H.; Joachimmeyer, E.; Roider, J.; Framme, C.; Schlenke, P.; Kirchner, H.; Lagua, H. Results of vitrectomy and the no-touch-technique using autologous adjuvants in macular hole treatment. Int. Ophthalmol. 2001, 24, 151-159. [CrossRef] [PubMed]

50. Anitua, E.; de la Fuente, M.; Muruzabal, F.; Sanchez-Avila, R.M.; Merayo-Lloves, J.; Azkargorta, M.; Elortza, F.; Orive, G. Differential profile of protein expression on human keratocytes treated with autologous serum and plasma rich in growth factors (PRGF). PLOS ONE 2018, 13, e0205073. [CrossRef]

51. Suarez-Barrio, C.; Del Olmo-Aguado, S.; Garcia-Perez, E.; de la Fuente, M.; Muruzabal, F.; Anitua, E.; Baamonde-Arbaiza, B.; Fernandez-Vega-Cueto, L.; Fernandez-Vega, L.; Merayo-Lloves, J. Antioxidant Role of PRGF on RPE Cells after Blue Light Insult as a Therapy for Neurodegenerative Diseases. Int. J. Mol. Sci. 2020, 21, 1021. [CrossRef] [PubMed] 